\title{
Contemporary robotic cardiac surgical training
}

Vinay Badhwar, MD, ${ }^{\mathrm{a}}$ Lawrence M. Wei, MD, ${ }^{\mathrm{a}}$ Arnar Geirsson, MD, ${ }^{\mathrm{b}}$ Joseph A. Dearani, MD, Eugene A. Grossi, MD, ${ }^{\mathrm{d}}$ T. Sloane Guy, MD, ${ }^{\mathrm{e}}$ Husam H. Balkhy, MD, ${ }^{\mathrm{f}}$ A. Marc Gillnov, MD, ${ }^{\mathrm{g}}$ Francis P. Sutter, DO, ${ }^{\mathrm{h}}$ Serguei Melnitchouk, MD, ${ }^{\mathrm{i}}$ Johannes Bonatti, MD, ${ }^{\mathrm{j}}$ Douglas A. Murphy, MD, ${ }^{\mathrm{k}}$ and W. Randolph Chitwood, Jr, MD ${ }^{1}$

Since the first robotic cardiac operation was performed more than 2 decades ago, ${ }^{1}$ surgeons have experienced the introduction of several generations of robotic telemanipulation technology including multiple technique enhancements to include a wider array of cardiac operations and pathologies. There has been an accompanying need to refine education and training to adapt to this clinical and technological evolution. Recognizing the importance of these recent developments, both the American Association for Thoracic Surgery (AATS) and The Society of Thoracic Surgeons (STS) have established postgraduate training fellowship awards to address a growing interest in robotic cardiac surgery. The aim of this review is to provide contemporary consensus recommendations to address the unique challenges and opportunities for team-based robotic cardiac training.

\section{OBJECTIVE}

The goal of this document is to outline current pathways for advanced robotic cardiac surgery training to facilitate safe and immediate clinical application. The focus not only is on surgeon training but also relates to preparation of the entire surgical team to ensure reproducibility and sustainability of programmatic success with optimal patient safety and outcomes. This document does not aim to define credentialing recommendations, which remain under the purview of local hospital-based credentialing committees.

\footnotetext{
From the a Department of Cardiovascular and Thoracic Surgery, West Virginia University, Morgantown, WVa; ${ }^{b}$ Division of Cardiac Surgery, Yale-New Haven Health System, New Haven, Conn; ${ }^{\mathrm{c}}$ Division of Cardiovascular Surgery, Mayo Clinic, Rochester, Minn; ${ }^{\mathrm{d} D e p a r t m e n t}$ of Cardiothoracic Surgery, New York University, New York, NY; ${ }^{\mathrm{e}}$ Division of Cardiac Surgery, Thomas Jefferson University, Philadelphia, Pa; ${ }^{\mathrm{f}}$ Division of Cardiac Surgery, University of Chicago, Chicago, Ill; ${ }^{\mathrm{g}} \mathrm{De}-$ partment of Thoracic and Cardiovascular Surgery, Cleveland Clinic, Cleveland, Ohio; ${ }^{\mathrm{h}}$ Department of Cardiothoracic Surgery, Main Line Health Lankenau Medical Center, Wynnewood, Pa; ${ }^{\mathrm{i}}$ Division of Cardiac Surgery, Massachusetts General Hospital, Harvard University, Boston, Mass; ${ }^{\mathrm{j}}$ Department of Cardiothoracic Surgery, University of Pittsburgh, Pittsburgh, Pa; ${ }^{\mathrm{k}}$ Division of Cardiac Surgery, Emory University, Atlanta, Ga; and ${ }^{\mathrm{l} D e p a r t m e n t}$ of Cardiovascular Sciences, East Carolina University, Greenville, NC.

Received for publication Aug 31, 2021; revisions received Oct 16, 2021; accepted for publication Nov 2, 2021; available ahead of print Nov 10, 2021.

Address for reprints: Vinay Badhwar, MD, Department of Cardiovascular and Thoracic Surgery, West Virginia University, 1 Medical Center Dr, Morgantown, WV 26506 (E-mail: vinay.badhwar@wvumedicine.org).

J Thorac Cardiovasc Surg 2023;165:779-83

$0022-5223 / \$ 36.00$

Copyright (c) 2021 by The American Association for Thoracic Surgery https://doi.org/10.1016/j.jtcvs.2021.11.005
}

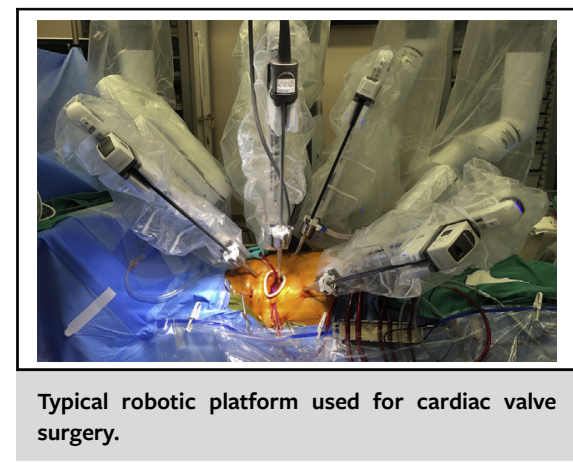

CENTRAL MESSAGE

Contemporary robotic cardiac training recommendations focus on safety and sustainability.

See Commentary on page 784 .

\section{EVOLUTION OF ROBOTIC CARDIAC SURGERY AND TRAINING}

The field of robotic cardiac surgery was ushered in by Carpentier and colleagues ${ }^{1}$ in early 1998 with the first successful robotic mitral valve repair (MVr). ${ }^{1}$ This was followed shortly thereafter by Mohr and colleagues ${ }^{2}$ and Loulmet and colleagues ${ }^{3}$ performing the first robotic-assisted coronary operations. Robotic MVr was subsequently championed by Nifong and colleagues, ${ }^{4}$ and this 20 -year effort has helped spawn the contributions of many others that have evolved intracardiac robotic surgery to a field still predominantly focused on robotic MVr, but one that now includes several other operations and concomitant procedures. Once performed by only a fraction of programs, currently more than $14 \%$ of all operations for primary mitral regurgitation in the United States are done robotically. ${ }^{5}$ The past 5 years have seen a multitude of advancements that go beyond the recent introduction of a new generation of surgical robots for cardiac application. In experienced centers, robotic $\mathrm{MVr}$ recently has been shown to be of equivalent cost and 1 -year durability to a sternotomy $\mathrm{MVr}$, conferring at least equal if not superior outcomes. It is now being safely and effectively applied to a growing number of older and more complex patients with increasing regularity. ${ }^{6-9}$ Likewise, procedural expansion into standard clinical practice now includes robotic-assisted mitral valve replacement, benign 
cardiac tumor excision, atrial septal defect closure, tricuspid valve operations, cryothermic Cox Maze ablation, and more recently in specific centers, septal myectomy, aortic valve replacement (AVR), and repair of anomalous pulmonary venous connection. As robotic $\mathrm{MVr}$ and other intracardiac operations become more common and standard of care in many experienced centers, there has been a commensurate growth in new surgeon interest in robotic training and program development.

In 2000, shortly after the initial robotic coronary experience in Paris and Leipzig, ${ }^{2,3}$ Falk and colleagues ${ }^{10}$ performed the first robotic-assisted coronary artery bypass grafting (CABG) on a beating heart. This paved the way for robotic-assisted minimally invasive direct coronary artery bypass (MIDCAB) procedures and totally endoscopic coronary artery bypass (TECAB) operations. ${ }^{11}$ Performance of TECAB to a level of expertise consistent with conventional CABG remains limited to only a few centers. To date, robotic-assisted MIDCAB, involving robotic left internal thoracic artery (LITA) takedown and a mini-thoracotomy direct vision hand-sewn beating-heart LITA to left anterior descending (LAD) anastomosis, represents the majority of robotic revascularization performed in recent years. ${ }^{12}$ Hybrid revascularization has become popular recently with excellent outcomes. This procedure combines robotic-assisted MIDCAB or TECAB LITA to LAD with percutaneous intervention to the right coronary or circumflex territories. ${ }^{13}$ There has been a similar increase in surgeon interest for program development in robotic revascularization.

The past decade has seen several programs attempting to commence robotic cardiac surgery. Some have been successful, and some have not. The consistent theme of programs that have not continued after an initial commencement have not been due to the open skill of the surgeon but to the lack of volume and experience of the specific case types for the extended robotic team to maintain competence and efficiency. In 2021, a single vendor manufactures Food and Drug Administration-approved robotic systems and instrumentation for cardiac surgery (da Vinci Surgical System), but many alternative robotic options are now emerging that may soon have cardiac applications. The past 5 years have seen robotic cardiac education change from being largely vendor facilitated to a current training environment with minimal direct vendor support. In the 6 years after initial robotic cardiac training consensus recommendations, ${ }^{14}$ vendorbased training availability has diminished, and the application of robotic cardiac surgery has evolved.

The goal of the following consensus is to assist the recent resurgence in interest in robotic cardiac surgery by providing contemporary recommendations for surgeon and team robotic cardiac development. The following principles and recommendations were derived from literature review, clinical and training experience, and unanimity of consensus by the co-authors.

\section{PRINCIPLES AND CURRENT PATHWAYS FOR} TEAM-BASED ROBOTIC CARDIAC TRAINING

Throughout the clinical advancements in robotic cardiac surgery, 2 pathways have emerged: robotic-assisted coronary revascularization and robotic-assisted valve and related concomitant intracardiac surgery. Often, but not always, these 2 pathways are performed by different surgeons with complementary but different surgical skills and levels of mastery. These are based on dedicated surgeon and team experience with commitment to each pathway, often with different referral patterns and sub-specialization. Both pathways may coexist in the same institution, or separately, as individual programs. For optimal safety and patient outcomes, initial entry into each pathway should be predicated on substantive surgeon and team institutional experience with related nonrobotic operations. Although robotic telemanipulation may provide enhanced visualization and access to cardiac structures, it does not substitute for the value of open and nonrobotic surgical experience.

\section{Team Composition}

Robotic programs require a substantial capital investment along with ongoing device maintenance and per patient costs. ${ }^{15}$ Therefore, for a program to be sustainable, there must exist both institutional and provider alignment in the commitment to education and training of staff, as well as to program development to ensure sustained patient volume. Programs that have had successful initiation and sustainability have strong administrative support, a clearly identified surgeon leader, and a dedicated bedside first assistant that may be a surgeon or allied health provider. Furthermore, successful programs have adequate access to operating room and robotic time of at least 1 day per week, and an initial limited number of dedicated team providers committed to the program including cardiac anesthesiology, scrub nurses or technologists, circulating nurses, and perfusionists. As each team member brings unique and complementary skills for programmatic success, it is ill advised to have several rotating team members participate during the initial phase of program commencement. Instead, the initial team members can train other team participants over time so as to not impact the workflow of cases and ensure temporal efficiency and patient safety.

\section{Minimum Requirements Before Program Initiation}

Before embarking on robotic revascularization program initiation and training, surgeons should have a minimum of 3 years of independent attending-level clinical practice or successful completion of a postgraduate robotic fellowship with robotic MIDCAB/TECAB concentration. Surgeons should have a core competency in both on-pump and off-pump sternotomy CABG including a minimum of 250 career cases as primary operator, 50 of which should 
be OPCAB, with an observed to expected mortality of 1 or less (Table 1). Additionally, experience with 25 career cases of minimally invasive CABG via left mini-thoracotomy is highly recommended but not required before program commencement.

Before embarking on robotic valve and intracardiac program initiation and training, surgeons should have a minimum of 3 years of independent attending-level clinical practice or successful completion of a postgraduate robotic fellowship with robotic valve concentration. Surgeons should have a core competency in open mitral valve operations that include MVr or mitral valve replacement, with or without concomitant operations including surgical ablation, of a minimum of 75 career cases as primary operator, 50 of which should be performed over the most recent 2 years, with an observed to expected mortality of 1 or less. Furthermore, it is highly recommended to have an experience of a minimum of 15 cases of mini-thoracotomy cardiac operations with peripheral cannulation for cardiopulmonary bypass over the most recent 2 years before program commencement (Table 1).

Before robotic program initiation of either pathway, institutional/program annual cardiac open heart volumes should be a minimum of 250 cases per year for a minimum of 3 years, with a dedicated team of institutionally based cardiac anesthesiologists with routine use of transesophageal echocardiography for all open operations, a dedicated team of institutionally based perfusionists, and immediate institutional access to advanced mechanical circulatory support (Table 1).

\section{Team Training and Development}

Successful robotic teams are often composed of individuals who have worked closely together before beginning robotic cardiac surgery, each with a track record of effective communication in the operating room. Individuals should demonstrate personal situational awareness regarding their impact and role on temporal efficiency and workflow. Selecting the correct team composition enables optimal focus on procedural progression and patient safety that lead to optimal patient outcome. The entire team should be included early in development of the robotic program to ensure dedication and enthusiasm of all members. Dry and wet laboratory training as well as comprehensive dry runs are important team training components. Clearly established verbal communication protocols, checklists, and individual team member roles often lead to the most effective robotic teams. ${ }^{16-21}$ These formative elements become even more important as programs advance toward procedural and case complexity (eg, advanced pathology or addition of concomitant procedures).

For contemporary robotic cardiac surgery, evaluating team and case effectiveness using metrics such as total operative time or technical or anatomic outcomes, as was done in the past, is insufficient today to enable effective learning and team progression. As each member of the team can develop unique skills and training to improve the efficient and safe performance of a robotic operation, a gradation in team proficiency can be measured more effectively by compartmentalizing operative steps and tracking each over time. Common steps that can be timed, tracked, and

TABLE 1. Recommended minimum surgeon experience and institutional resources before initiation of a robotic cardiac program

\begin{tabular}{|c|c|c|}
\hline & Robotic revascularization program & Robotic valve/intracardiac program \\
\hline $\begin{array}{c}\text { Training and } \\
\text { practice }\end{array}$ & $\begin{array}{l}\text { - American Board of Thoracic Surgery or equivalent } \\
\text { - } 3 \text { y of independent attending-level clinical practice or } \\
\text { a minimum 1-y postgraduate robotic cardiac } \\
\text { fellowship with robotic revascularization } \\
\text { concentration }\end{array}$ & $\begin{array}{l}\text { - American Board of Thoracic Surgery or equivalent } \\
\text { - } 3 \text { y of independent attending-level clinical practice or a minimum } \\
\text { 1-y postgraduate robotic cardiac fellowship with robotic valve } \\
\text { concentration }\end{array}$ \\
\hline $\begin{array}{l}\text { Clinical } \\
\text { experience }\end{array}$ & $\begin{array}{l}250 \text { career cases of coronary revascularization as } \\
\text { primary operator (on or off pump) with an } \mathrm{O} / \mathrm{E} \text { of } \leq 1 \text {, } \\
\text { of which } 50 \text { should be off pump }\end{array}$ & $\begin{array}{l}\text { - } 75 \text { career cases of } \mathrm{MVr} \text { or replacement, with or without } \\
\text { concomitant procedures that may include surgical ablation, with } \\
\text { an } \mathrm{O} / \mathrm{E} \text { of } \leq 1 \text {, of which } 50 \text { should be within the prior } 2 \mathrm{y} \\
\text { - } 15 \text { cases of valve/intracardiac operations performed via } \\
\text { minimally invasive thoracotomy involving peripheral } \\
\text { cardiopulmonary bypass performed within the prior } 2 \text { y with an } \\
\text { O/E of } \leq 1\end{array}$ \\
\hline $\begin{array}{r}\text { Institutional } \\
\text { resources }\end{array}$ & $\begin{array}{l}\text { - } 250 \text { adult cardiac surgical cases per year for a } \\
\text { minimum of } 3 \mathrm{y} \\
\text { - A dedicated team of institutionally based cardiac } \\
\text { anesthesiologists practicing routine use of } \\
\text { transesophageal echocardiography } \\
\text { - A dedicated team of institutionally based perfusionists } \\
\text { - Immediate institutional access to advanced } \\
\text { mechanical circulatory support }\end{array}$ & $\begin{array}{l}\text { - } 250 \text { adult cardiac surgical cases per year for a minimum of } 3 \mathrm{y} \\
\text { - A dedicated team of institutionally based cardiac } \\
\text { anesthesiologists practicing routine use of transesophageal } \\
\text { echocardiography } \\
\text { - A dedicated team of institutionally based perfusionists } \\
\text { - Immediate institutional access to advanced mechanical } \\
\text { circulatory support }\end{array}$ \\
\hline
\end{tabular}

$O / E$, Observed to expected; $M V r$, mitral valve repair. 
optimized for either robotic cardiac pathway may include the following: (1) operative table set up; (2) patient operating room arrival, anesthetic induction including lines (wheels in to anesthesia release); (3) robot sterile draping; (4) patient positioning and topographic marking; (5) skin incision to port placement completion; (6) robotic docking from resting room position to table side lock; and (7) robotic port locking and initial instrument positioning until console control has been established.

For the robotic revascularization pathway, although quality of LITA harvest, revision-free anastomosis creation, and bloodless closure are of paramount importance, additional steps that are recommended to be timed, tracked, and optimized over the program's experience may include (1) LITA start to heparin; (2) heparin to LITA fixation to pericardium or epicardium; (3) mini-thoracotomy to initial coronary incision for MIDCAB or heparin to initial coronary incision for TECAB; (4) initial coronary incision to LITA clamp release; and (5) LITA clamp release to closure (Table 2).

For the robotic valve/intracardiac pathway, although intracardiac anatomic valve or rhythm restoration and bloodless closure remains of paramount importance, additional steps that are recommended to be timed, tracked, and optimized over the program's experience may include (1) skin incision to heparin; (2) cannulation initiation to crossclamp; (3) initial atrial incision to final mitral exposure; (4) first annular suture placement to completed ring or prosthesis release (excluding leaflet repair or resection); and (5) first atrial closure suture to completion of atrial closure (Table 2).

It is further recommended that robotic teams should start with straightforward cases (eg, nonintramyocardial LAD, focal posterior leaflet or annular MVr pathology) to establish procedural homogeneity. This is not only for patient safety but also to enable consistent compartmental time tracking for each procedural step. Progression of case complexity or procedural advancement should only be done once the team has demonstrated improvement in each compartmental step with time reduction to a consistent plateau, often after a minimum of 10 to 20 cases. Team coordination and leadership are essential to maintain an environment of patient safety as one introduces new techniques or technology. ${ }^{22,23}$
Stepwise introduction of technical advancement with confirmation of acceptance and safe adoption using the similar tools is recommended before adding further advancements. Critical review of outcomes should occur on a regular basis especially in early phases of program development. It is of particular importance for a program to track their robotic clamp and cardiopulmonary bypass times to ensure that these eventually approach institutional congruency with similar operations performed via sternotomy.

\section{Core Competency Training Levels}

The principles established for robotic programmatic advancement noted are meant to be robotic device and vendor agnostic. Team training may be accessed currently through the AATS, the STS, established institutional robotic training programs, or a combination of any or all of these options. The current robotic cardiac environment is limited to use of the da Vinci surgical system manufactured by Intuitive. Therefore, the nomenclature for the levels of core competency training used by Intuitive has been adopted for the sake of consistency, although the principles of each level may be applicable to future robotic technology.

Basic, or TR 100 level training, involves initial technology training of robotic technical skill through the use of computer simulation and instruction by a dedicated robotic vendor trainer. This is often accomplished either at a designated vendor facility and may include the surgeon and robotic team or at the surgeon's hospital. The TR 200 level training is a surgeon-led peer-to-peer training that combines core robotic technology training with an introduction of surgical clinical application that includes technical skills. This is often accomplished through a combination of case observation at a robotic center of excellence for either or both robotic cardiac pathways and a team-based simulated robotic case(s) that may include cadaveric specimens. The TR 300 level training involves procedure training that specifically addresses robotic application to specific clinical procedures. This may be surgeon-led and may involve simulated cases on-site for the team to advance proficiency of steps of the procedure that furthers team understanding of the components of the robotic system, console operation,

TABLE 2. Compartmentalized steps specific to robotic revascularization and valve/intracardiac operations

\begin{tabular}{lc}
\hline \multicolumn{1}{c}{ Robotic revascularization operations } & Robotic valve/intracardiac operations \\
\hline - Commencement of LITA harvest to heparin administration & $\bullet$ Skin incision to heparin \\
- Heparin administration to LITA fixation to pericardium or epicardium & $\bullet$ Initial atrial incision to final mitral exposure \\
- Mini-thoracotomy skin incision to initial coronary incision for MIDCAB & $\bullet$ First annular suture placement to completed ring or \\
or heparin to initial coronary incision for TECAB & prosthesis release (excluding leaflet repair or resection) \\
\hline - LITA clamp release to closure completion & $\bullet$ First atrial closure suture to completion of atrial closure \\
\hline LITA, Left internal thoracic artery; $M I D C A B$, minimally invasive coronary artery bypass; TECAB, total endoscopic coronary artery bypass.
\end{tabular}


troubleshooting, tableside management including suture management arm manipulation troubleshooting, console operation, and telemanipulation. The TR 400 level involves surgeon-led procedure refinement training for procedures that the team is already performing with the robotic system. This may involve the use of surgeon proctors. Finally, the optional TR 500 level involves surgeon-led masters training and case observation that may serve to enhance a technique or expand procedural depth or technical advancement.

In 2019, with vendor support, both the AATS Foundation and the STS Thoracic Surgery Foundation launched focused postgraduate fellowship training programs in robotic cardiac surgery with minimum recommendations for programmatic candidacy and post-training suggestions consistent with the principles outlined in this document.

\section{FUTURE DIRECTIONS}

The safety, effectiveness, and sustainability of a robotic cardiac surgical program may be established by adherence to the principles outlined in this expert consensus review. The importance of a harmonious collaboration between the institution and the surgical team of providers cannot be overstated. If a mutually supportive relationship can be nurtured, along with that of the skill of the robotic team, programmatic advancement and introduction of new techniques can be readily achieved. ${ }^{24}$ As part of the establishment of a teambased robotic program, it is recommended the team track and report patient outcomes and quality through participation in a national cardiac surgery registry or public reporting. Educating one's team, referring providers, patients, and the surgical community as a whole as techniques evolve is an essential part of leadership in robotic cardiac surgery.

\section{Conflict of Interest Statement}

V.B. serves as a nonremunerative consultant to Abbott. E.A.G. serves as a consultant to Edwards Lifesciences and Medtronic and receives royalties from Medtronic. T.S.G., H.H.B., F.P.S., and D.A.M. serve as consultants to Intuitive. W.R.C. serves as a consultant to Edwards Lifesciences, Intuitive, and Medtronic. All other authors reported no conflicts of interest.

The Journal policy requires editors and reviewers to disclose conflicts of interest and to decline handling or reviewing manuscripts for which they may have a conflict of interest. The editors and reviewers of this article have no conflicts of interest.

The authors thank Peter Carnegie for several important contributions to robotic cardiac training.

\section{References}

1. Carpentier A, Loulmet D, Aupècle B, Kieffer JP, Tournay D, Guibourt P, et al. [Computer assisted open heart surgery. First case operated on with success]. $C$ R Acad Sci III. 1998;321:437-42.
2. Mohr FW, Falk V, Diegeler A, Autschback R. Computer-enhanced coronary artery bypass surgery. J Thorac Cardiovasc Surg. 1999;117:1212-4.

3. Loulmet D, Carpentier A, d'Attellis N, Berrebi A, Cardon C, Ponzio O, et al. Endoscopic coronary artery bypass grafting with the aid of robotic assisted instruments. J Thorac Cardiovasc Surg. 1999;118:4-10.

4. Nifong LW, Chu VF, Bailey BM, Maziarz DM, Sorrell VL, Holbert D, et al. Robotic mitral valve repair: experience with the da Vinci system. Ann Thorac Surg. 2003; $75: 438-42$

5. Gammie JS, Chikwe J, Badhwar V, Thibault DP, Vemulapalli S, Thourani VH, et al. Isolated mitral valve surgery: The Society of Thoracic Surgeons Adult Cardiac Surgery Database Analysis. Ann Thorac Surg. 2018;106:716-27.

6. Coyan G, Wei LM, Althouse A, Roberts HG, Schauble D, Murashita T, et al. Robotic mitral valve operations by experienced surgeons are cost-neutral and durable at 1 year. J Thorac Cardiovasc Surg. 2018;156:1040-7.

7. Gillinov AM, Mihaljevic T, Javadikasgari H, Suri RM, Mick SL, Navia JL, et al. Early results of robotically assisted mitral valve surgery: analysis of the first 1000 cases. J Thorac Cardiovasc Surg. 2018;155:82-91.e2.

8. Wang A, Brennan JM, Zhang S, Jung SH, Yerokun B, Cox ML, et al. Robotic mitral valve repair in older individuals: an analysis of The Society of Thoracic Surgeons Database. Ann Thorac Surg. 2018;106:1388-93.

9. Loulmet DF, Ranganath NK, Neuburger PJ, Nampiaparampil RG, Galloway AC, Grossi EA. Can complex mitral valve repair be performed with robotics? An institution's experience utilizing a dedicated team approach in 500 patients. Eur J Cardiothorac Surg. 2019;56:470-8.

10. Falk V, Diegeler A, Walther T, Banusch J, Brucerius J, Raumans J, et al. Total endoscopic computer enhanced coronary artery bypass grafting. Eur J Cardiothorac Surg. 2000;17:38-45.

11. Balkhy HH, Nisivaco S, Kitahara H, McCrorey M, Patel B. Robotic multivesse endoscopic coronary bypass: impact of a beating-heart approach with connectors. Ann Thorac Surg. 2019;108:67-73.

12. Whellan DJ, McCarey MM, Taylor BS, Rosengart TK, Wallance AS Shroyer AL, et al. Trends in robotic-assisted coronary artery bypass grafts: a study of The Society of Thoracic Surgeons Adult Cardiac Surgery Database, 2006-2012. Ann Thorac Surg. 2016;102:140-6.

13. Kitahara H, Hirai T, McCrorey M, Patel B, Nisivaco S, Nathan S, et al. Hybrid coronary revascularization: midterm outcomes of robotic multivessel bypass and percutaneous interventions. J Thorac Cardiovasc Surg. 2019;157: 1829-18236.e1.

14. Rodriguez E, Nifong LW, Bonatti J, Casula R, Falk V, Folliguet TA, et al. Pathway for surgeons and programs to establish and maintain a successful robot-assisted adult cardiac surgery program. J Thorac Cardiovasc Surg. 2016; $152: 9-13$

15. Barbash GI, Glied SA. New technology and health care costs - the case of robotassisted surgery. N Engl J Med. 2010;363:701-4.

16. Gawande AA, Zinner MJ, Studdert DM, Brennan TA. Analysis of errors reported by surgeons at three teaching hospitals. Surgery. 2003;133:614-21.

17. Ziewacz JE, Arriaga AF, Bader AM, Berry WR, Edmondson L, Wong JM, et al Crisis checklists for the operating room: development and pilot testing. J Am Coll Surg. 2011;213:212-7.e10.

18. Yaffee DW, Loulmet DF, Kelly LA, Ward AF, Ursomanno PA, Rabinovich AE, et al. Can the learning curve of totally endoscopic robotic mitral valve repair be short-circuited? Innovations (Phila). 2014;9:43-8.

19. Toker A. Robotic thoracic surgery: from the perspectives of European chest surgeons. J Thorac Dis. 2014;6:S211-6.

20. Brook NR, Dell'Oglio P, Barod R, Collins J, Mottrie A. Comprehensive training in robotic surgery. Curr Opin Urol. 2019;29:1-9.

21. Collins JW, Wisz P. Training in robotic surgery, replicating the airline industry How far have we come? World J Urol. 2020;38:1645-51.

22. Valdis M, Chu MW, Schlachta C, Kiaii B. Evaluation of robotic cardiac surgery simulation training: a randomized controlled trial. J Thorac Cardiovasc Surg. 2016;151:1498-505.e2.

23. Lehr EJ, Guy TS, Smith RL, Grossi EA, Shemin RJ, Rodriguez E, et al. Minimally invasive mitral valve surgery III: training and robotic-assisted approaches. Innovations (Phila). 2016;11:260-7.

24. Badhwar V, Wei LM, Cook CC, Hayanga JWA, Daggubati R, Sengupta PP, et al. Robotic aortic valve replacement. J Thorac Cardiovasc Surg. 2021; $161: 1753-9$

Key Words: cardiac surgery, education, robotic, training 